\title{
Essa roubalheira em Brasília, ninguém merece! Análise sociocognitivista de uma construção sintática
}

\author{
This embezzlement in Brasília, no one deserves (it): \\ a sociocognitive analysis of a syntactic construction \\ José Vicente Santos MENDES** \\ Universidade Federal de Viçosa (UFV)
}

\begin{abstract}
RESUMO: O trabalho analisa a construção moralizante ou moralizadora $(\mathrm{CM})$ e seu nicho na estrutura argumental do Português do Brasil. Pretende estabelecer o padrão sintático e semântico da $\mathrm{CM}$ e o pareamento forma-significado que lhe é inerente, inclusive no que diz respeito a dimensões prosódicas e pragmáticas. Além disso, propõe uma rede de construções da qual a CM faz parte. Um banco de dados amostral de mais de 550 instâncias recolhidas na fala espontânea oral e escrita é usado para corroborar, com inspiração na linguística de corpus, os ganhos teóricos da empreitada, e ressaltar a abordagem dos modelos de uso que defendemos.
\end{abstract}

PALAVRAS-CHAVE: Construção sintática. Sociocognitivismo. Modelos baseados no uso. Português do Brasil.

ABSTRACT: The study analyzes the moralizing or moralizer construction (MC) and its niche in the argument structure of Brazilian Portuguese. It aims at establishing the syntactic and semantic pattern of MC, and the form-meaning pairing inherent to it, not forgetting to encompass the prosodic and pragmatic dimensions that are concerned. Besides, it proposes a network of constructions to which MC belongs. A sample database of more than 550 instances amassed in spontaneous oral and written verbal language use is resorted to so as to corroborate, inspired in corpus linguistics, the theoretical gain from the enterprise, and to stress the usage based model approach we defend.

KEYWORDS: Syntactic construction. Sociocognitivism. Usage based models. Brazilian Portuguese.

\section{Introdução}

Imaginemos o seguinte minidiálogo entre dois compatriotas nossos:

A: - Você viu? O Judiciário se concedeu outro aumento bem gordo. O Legislativo copiou a medida. E agora é o Executivo que está pleiteando "reposição salarial”!!!

B: - Eu fico revoltado... Essa roubalheira em Brasília, ninguém merece!

\footnotetext{
* Esta pesquisa foi o resultado de um ano e meio em que trabalhei no então mestrado em linguística da Universidade Federal de Juiz de Fora, de maio de 2005 a setembro de 2006, enquanto bolsista CAPES PRODOC recém-doutor. Ela foi aceita como capítulo de livro para o volume Cognição e Uso, após evento com o mesmo nome que reuniu pesquisadores em linguística cognitiva mineiros na Federal de Viçosa. O volume estava sendo editado por Heliana Mello, Luiz Fernando Matos Rocha e Luciana Ávila. Após vários contratempos e imprevistos de inúmeras ordens, entretanto, o volume acabou não vindo ao prelo.

** Doutorado em Ciência da Cognição; professor adjunto II da Universidade Federal de Viçosa (UFV), Departamento de Letras e Artes. Viçosa - MG - Brasil. Email: vicente.mendes@ufv.br.
} 
A fala de B é rápida no gatilho para deslanchar na mente de A e de qualquer pessoa que pudesse estar ouvindo essa conversa inventada, porém altamente plausível no uso real da língua, um emaranhado de frames, molduras, cenas e enquadres comunicativos que remete a uma significação rica e bem particular na dinâmica de usar a forma linguística para guiar a semiose verbal no jogo de linguagem que os interactantes jogam corriqueira, sociohistórica e situadamente na cultura do nosso país. Ou seja, B ou qualquer outro brasileiro não terá a menor dificuldade para coconstruir com $\mathrm{A}$ o sentido de que os governantes na capital da nação vivem tomando medidas em benefício próprio em vez de defender os direitos do povo, para o quê, em tese, teriam sido eleitos; de que a maioria esmagadora dos trabalhadores faz mágica para sobreviver com salário mínimo enquanto quem já ganha quantias vultosas todo mês sempre acha que não é suficiente e dá um jeitinho para ter mais vantagens ainda no sistema de injustíssima distribuição de renda que conhecemos de perto desde sempre, etc. Toda essa carga de potencialidade de conteúdo é trazida para a interação através do uso da construção sintática 'Essa roubalheira em Brasília, ninguém merece!', a qual chamei Construção Moralizante/Moralizadora, de agora em diante $\mathrm{CM}$.

Sob esse prisma, minha investigação resgata um insight genial do pai da ciência da linguagem, Ferdinand de Saussure, ao constatar a quase onipresença (pois temos que levar em consideração usos menos frequentes, contudo, motivados, também inerentes ao sistema, tais como, p. ex., as onomatopeias) da convencionalidade do signo nas línguas naturais. Entretanto, conforme bem explica a linguística cognitiva contemporânea, o pareamento forma-sentido em qualquer língua vai muito além das palavras. $\mathrm{Na}$ verdade, ele se desloca desde a esfera dos morfemas até a dimensão dos gêneros textuais/tipos discursivos, em amarramentos convencionalizados no uso de significante (forma/expressão) e significado (conteúdo/sentido). A CM, sobre o que discorro, situa-se no nível sentencial nessa escala que vai do micro ao macro linguístico. Resumindo, em esforço hercúleo de concisão para efeito didático, os principais postulados do arcabouço teórico da Gramática das Construções, doravante GC, poderíamos talvez mencionar: ao contrário do que defende sua maior rival epistemológica - a Gramática Universal do paradigma chomskyano -, a GC aposta forte na simbologia da linguagem humana. A Gramática é um inventário de pareamentos forma/significante/expressão - sentido/modos de significação/função recorrentes no desempenho e na competência comunicativa dos falantes nativos da língua, que ancoram a noção de 'valor' da metáfora do jogo de xadrez de Saussure no contextualismo/funcionalismo/compromisso com a pragmática próprio da linguística cognitiva contemporânea ${ }^{1}$. Assim, a sintaxe não é estanque nem o único módulo gerativo de competência; antes ela emerge no uso, num continuum entre léxico e gramática, semântica e pragmática, integrando uma rede de unidades construcionais que vão desde o morfema até o discurso. Não existe mais a diferença entre núcleo e periferia. Tanto elementos mais marginais da rede quanto suas contrapartes mais previsíveis precisam ser tratados de maneira comum, com a mesma metodologia e rigor. Reconhece-se uma concomitância dos processos de composicionalidade e multidirecionalidade no arranjo de esquemas conceptuais e formais originadores das construções. E, por último, percebemse a motivação e a herança de traços nas relações entre as unidades construcionais que compõem a gramática de uma língua, motivação e herança essas que se estabelecem através de projeções e elos de naturezas diferenciadas. $\mathrm{O}$ objeto de análise do presente artigo localiza-se no âmbito sintático desse paradigma escalar/gradativo/radial.

\footnotetext{
${ }^{1}$ Ver Goldberg (1995; 2006), Jackendoff (2002; 2012), Salomão (2005; 2009), Fauconnier; Turner (2002), Marcuschi (2007) e Mendes (inédito).
} 
Como apreensão primeira do meu objeto investigativo, poderíamos definir a CM como qualquer sentença que se encaixe no pareamento forma-função do padrão \{Tópico [SN/S] + Comentário ['ninguém'V]\}. Assim, o título da presente contribuição exemplifica essa estrutura. O Tópico, o assunto que se põe em pauta, é 'essa roubalheira em Brasília', e aquilo que o usuário da língua diz na interação sobre esse Tópico, o Comentário, aparentemente telegráfico, é 'ninguém merece'. O exemplo, obtido via introspecção, dá uma ideia da força ilocucionária desse padrão na NURC (norma urbana culta) em suas modalidades tanto oral quanto escrita hoje. Trata-se sem dúvida de repudiar, com veemência, um certo estado de coisas que se erige como tema da fala contextualizada no transcorrer de um dado evento comunicativo. Daí o nome 'moralizante' / 'moralizador' do padrão. E, caso o interlocutor coadune com essa atitude do locutor, a força perlocucionária da construção será a de ganhar a adesão do interactante na crítica que faz o falante/escritor ao objeto/indivíduo ou status quo referenciados pelo Tópico.

Passemos agora ao roteiro de minha despretensiosa contribuição ao presente periódico. Tendo em vista que já sintetizei, grosso modo, o arcabouço teórico encampado pela pesquisa, nos itens subsequentes, tratarei de, primeiro, caracterizar mais amiúde o item lexical construcional sobre o qual me debrucei de maio de 2005 a setembro de 2006. Em seguida, situarei a CM, especificamente, face à rede de construções que, proponho, lhe são adjacentes. Por último, teço breves comentários sobre o que poderia ser feito a fim de fortalecer os resultados da pesquisa na comprovação da hipótese formulada e sugerida pela investigação aqui trazida à tona, mas aproveito a conclusão também para pontuar o ganho teórico de tudo que já pode ser verificado como fruto dessa jornada.

\section{O objeto de perquirição: a $\mathrm{CM}$ e a rede de construções sintáticas em que se insere}

O primeiro passo no trato do fenômeno em questão consistiu em examinar como as dicotomias Foco-Pressuposto, Sujeito-Predicado e Tópico-Comentário se relacionam com a CM. Em seguida, delimitei o lugar especificamente ocupado pela CM na rede de construções que insemina a infinidade de pareamentos forma-sentido vigentes no Português do Brasil contemporâneo. Parti então para a coleta de um esboço de corpus, vale dizer, de um banco de dados amostral de instâncias da CM, predominantemente eletrônicas, atestadas em blogs mediante ferramentas de busca de uso comum tais como Google, Yahoo e similares. Mas também recolhi ocorrências observadas/percebidas em interação oral face a face, bem como em telenovelas, telejornais, difusões de rádio, artigos de revistas etc. De posse desse banco de dados, descrevi que tipos de expressões podem instanciar os constituintes 'Tópico' e 'Verbo do Comentário' da CM, delimitando o nexo recorrente que existe entre eles dentro do padrão sob escrutínio. Formulei, em consequência, a hipótese de uma rede de construções sentenciais na qual se localiza a CM, a partir da distinção primeira e precípua entre o que cunhei serem Construções de Realce (CR) e Construções Lineares Comuns (CLC). Postulo uma motivação de ênfase no recorte comunicativo da predicação para a escolha por um tipo em detrimento do outro no uso da língua. Tudo começa com o fluxo da informação e com o concomitante ponto de vista adotado pelo falante num dado momento da interação verbal. Isto é: se o falante julgar que a situação exige que ele jogue o holofote sobre (chame especial atenção do interlocutor para) um determinado elemento da cena, automaticamente uma CR será preferida. Caso contrário, decidirá que cabe bem no contexto interativo uma simples CLC.

Em síntese: no nível sentencial de análise, a hipótese formulada foi a de que há duas categorias abstratas elementares, quais sejam, as CR e as CLC. A CM é um nódulo de 
uma rede de construções topicalizadas universais, um subtipo de padrão instanciador de CR. Como características de forma e de sentido, respectivamente, a CM apresenta os seguintes traços:

FORMA: realce prosódico para o Tópico - com contorno entoacional específico seguido de pausa - associado à ordem específica de constituintes, em que o sujeito do Comentário é quantificado universalmente pelo operador negativo 'ninguém', seguido de verbo sem objeto direto posposto conjugado na $3^{\text {a }}$ pessoa do singular.

SENTIDO: avaliação negativa enfática via Comentário da entidade ou do estado de coisas a que o Tópico se refere. Cumpre notar que, haja vista a indistinção entre semântica e pragmática que abraçamos, muitas vezes (quase sempre?) o referente da instanciação gramatical do Tópico (SN/S) remeterá a toda uma situação, ou a um arranjo de cenas, molduras e enquadres conforme tenha vindo sendo conduzida até o momento da enunciação da CM a coconstrução do sentido pela parceria entre os interactantes (CLARK, 1996; MENDES, 2008/2005).

Comprovou-se preliminarmente a hipótese através da análise dos dados. A amostra de ocorrências supracitada soma em torno de 550 e poucas instâncias da CM. Como corolário, chegou-se a uma arquitetura de construções baseada, repito, no ponto de vista do fluxo informacional (LAMBRECHT, 1994, e seguidores) que desdobra a oposição fundamental entre CLC e CR. A categoria CLC engloba todas as sentenças de predicação neutra, sem enfatizar por prosódia e/ou linearidade particular qualquer de seus constituintes. A categoria CR inclui construções de ênfase meramente prosódica de um lado, e, de outro, um subgrupo formado por construções que associam à ênfase prosódica um ordenamento idiossincrático de constituintes: construções clivadas, pseudoclivadas e topicalizadas. Assim, as topicalizadas são um tipo determinado de CR nessa hierarquia de pareamentos forma-sentido desencadeada pela perspectivização de "holofote" ou de "iluminação regular/distribuída" com que o usuário da língua decide recortar a predicação que o enunciado sinaliza para guiar a semiose verbal.

Em oposição a uma construção Sujeito-Predicado Neutra - a estrutura fundamental de CLC, ex. 'A bomba destruiu a catedral' -, o usuário da língua pode preferir (achando-a mais pertinente ao contexto real de fala em que vier a se encontrar) uma construção Tópico-Comentário, ex. 'A catedral, a bomba destruiu', uma das estruturas fundamentais da categoria CR. Quando o sujeito do Comentário, em vez de ser uma descrição referencial do tipo 'o/a X', é quantificado universalmente, propomos no presente artigo que se trate da classe de Construções Topicalizadas Universais, que se dividem em dois grupos: as positivas e as negativas. De um lado temos as CTUP (Construções Topicalizadas Universais Positivas), que predicam afirmativamente. Elas se dividem em dois subtipos: as Diretas (CTUPD) e as Retóricas (CTUPR), dependendo da expressão linguística que instancia o Sujeito do seu Comentário. Tanto as CTUPD quanto as CTUPR coincidem quase totalmente nas especificações da faceta forma. Sintaticamente o Tópico virá sempre materializado na forma de um SN ou de uma S. O que as distingue é que o Sujeito do Comentário é o quantificador universal 'todo mundo' naquelas, enquanto que nessas vem vestido de 'forma Qu' + 'não' + interrogação. O verbo do Comentário tanto das CTUPD quanto das CTUPR é sempre 'quer', 'deseja', 'cobiça' ou afim. E ambas coincidem totalmente nas especificações da faceta sentido: a carga semântico-pragmática é a ênfase nos atributos bons (o que só será definível em última análise, contextualmente) da entidade ou do estado de coisas que o Tópico erige como assunto do enunciado. 
Exemplos desses itens construcionais da rede:

Emprego com salário líquido de \$22.000/mês, todo mundo quer. CTUPD

Casa, comida e roupa lavada de graça pro resto da vida, quem não quer? CTUPR

Quando o Comentário da Construção predica a carga semântica que o verbo carreia de um argumento interno universal sob o escopo de uma negação, temos a categoria de CTUN (Construções Topicalizadas Universais Negativas). Nessa classe, o verbo que ocorre mais prototipicamente é 'merecer'. Em gradação do mais prototípico para o menos prototípico temos 'merecer' $>$ 'aturar'/aguentar' > 'escolher' $>$ 'acreditar'. As CTUN também se dividem nos subtipos Diretas e Retóricas, nos mesmos moldes das CTUP. Exemplifico aqui essa outra faixa de radialidade da rede:

\section{Porque... \{meu pai e minha mãe, ninguém merece $\}^{2}$. CM $=$ CTUND prototípica Quatro da madrugada e o sono não chega, ninguém aguenta. CTUND - prototípica $^{3}$ Traição do parceiro depois de 11 anos de vida conjugal, ninguém atura. CTUND - - prototípica A fábrica pedir falência te botando no olho da rua, ninguém escolhe. CTUND - - - prototípica A quantidade de aborto clandestino perigoso por aí, ninguém acredita. CTUND - - - - prototípica}

Resumindo: na faceta forma, as CTUND vão apresentar a seguinte sintaxe: Tópico [SN/S] + Comentário [Sujeito = Quantificador universal negativo 'ninguém' + Verbo 'merece/aguenta/atura/escolhe/acredita]. Já quanto à faceta Semântica-Pragmática, as CTUND têm a força ilocucionária de criticar veementemente um estado de coisas que o falante julga necessário abolir por considerá-lo imoral, amoral ou indesejável por qualquer outro motivo. Corolário, o nome 'moralizante / moralizadora' que cunha a construção prototípica desse subpadrão de CR. E a força perlocucionária de adesão a tal crítica, de no mínimo, altíssima tendência no uso.

Finalmente, temos o último subtipo de Construção da rede que postulo. Ex.: Com tanto esquema de corrupção ao seu redor, quem resiste? Trata-se aqui da subclasse CTUNR (Construção Topicalizada Universal Negativa Retórica). Suas características da faceta Sintaxe: Tópico [SN/S/SPrep] Comentário [forma Qu 'quem' + Verbo 'resiste/rejeita/recusa' + interrogação]. Suas características da faceta SemânticaPragmática: defender a própria face (BUBLITZ, 2001; MATHEWS, 1997; LEVINSON, 1983; BROWN; LEVINSON, 1978) ou a face alheia na tentativa de justificar o envolvimento próprio ou de terceiros em atos, digamos pouco louváveis, indecorosos, recrimináveis, enfim, abomináveis por preceitos idealizados da ética, moral e bons costumes. Veja o quão natural seria a recriminação de A e a réplica de B:

\section{A: - Mas até você pegando propina, cara!, ninguém merece... \\ B: - Também, com tanto dinheiro sujo dando mole, quem resiste/rejeita/recusa?}

Voltando meu foco para o objeto investigativo deste artigo, a CM = CTUND, e desconsiderando descrições dos galhos fronteiriços de construções topicalizadas que lhe são limítrofes, constata-se que se trata de um padrão amalgamador de forma e sentido cujas facetas estrutura sintática e estrutura argumental, ligadas em correspondência, podem ser delimitadas de acordo com o diagrama abaixo:

\footnotetext{
${ }^{2}$ Instância colhida aos 21/10/2005 na fala espontânea, em conversa face a face, durante discussão sobre desentendimentos familiares.

${ }^{3}$ Entendo prototipicidade/prototipia neste trabalho como maior frequência de uso comparativamente a outras formas atestadas no banco amostral de dados.
} 


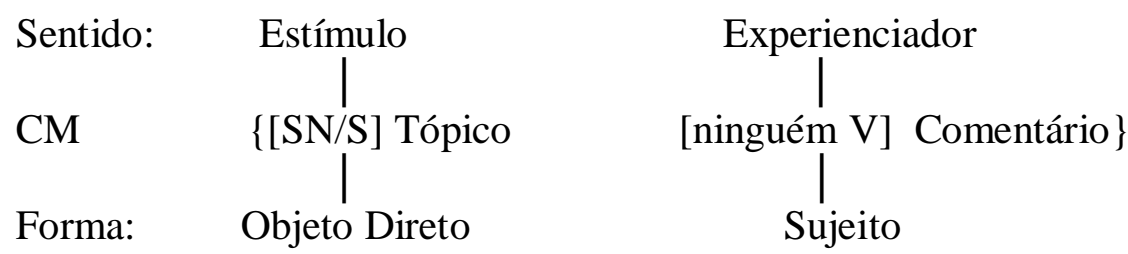

Nesses termos, a CM, como instanciadora do padrão genérico CTUND (Construção Topicalizada Universal Negativa Direta) faz o elo entre uma estrutura argumental envolvendo um ser que experimenta um dado estímulo, e uma estrutura gramatical na qual o Experienciador semântico equivale ao Sujeito sintático do Comentário a nível comunicativo, e o Estímulo semântico equivale ao objeto direto (categoria sintática) do verbo, complemento que ocorre como vazio fonológico-morfossintático na sentença Comentário, mas vem destacado como Tópico da construção, recebendo assim realce informacional. $\mathrm{O}$ emparelhamento de forma-potencialidade de sentido que a $\mathrm{CM}$ promove une duas facetas de um padrão inseminador do uso linguístico: uma faceta é a estrutura gramatical da construção, em que um objeto direto é destacado como Tópico à esquerda de uma sentença Comentário cujo sujeito é o quantificador universal negativo 'ninguém' e cujo verbo não tem argumento interno especificado fonológico-morfossintaticamente posposto ao predicador. Na faceta estrutura argumental, estabelece-se a relação concisa e nítida, como um tiro único e certeiro, entre um Estímulo e o seu Experienciador cognitivo, sensorial ou emocional, ligados por uma avaliação de repulsa enfática.

Perseguindo a metodologia inaugurada por Langacker (1988) e adotada em Mendes (1998, 2011), Barlow e Kemmer (2000) e tantos outros defensores dos modelos de uso, além das ocorrências da CM obtidas via reflexão pessoal, busquei exemplos atestados na fala do cotidiano que pudessem comprovar a hipótese de que a CM de fato consiste em uma entrada lexical específica na gramática particular dos falantes do Português do Brasil (PB) no que tange à deriva da língua na variante padrão oral e escrita (in)formal hoje.

Valendo-me, sobretudo, de ferramentas de busca abertas tais como Alta Vista, Terra, Uol e congêneres, cujo foco recai sobre o gênero textual atualíssimo de diários cibernéticos em linha (blogs), porém também registrando ocorrências espontâneas na fala em interação face a face e em registros midiáticos, e na escrita mais formal (jornais e revistas) da rede construcional em evidência, arrolei pouco mais de 550 instâncias do fenômeno, das quais reproduzo aqui apenas uma ${ }^{4}$.

Uma instância ilustrativa está transcrita abaixo, a partir de vídeo cedido, mediante interpelação, pelo Centro de Documentação da Rede Globo, Rio de Janeiro ${ }^{5}$. Meu intuito é mostrar o quão natural se revela o uso da CM nas trocas de turno do diálogo em questão, além de evidenciar a força ilocucionária intrínseca do padrão na construção do significado em cooperação pelos interactantes, e, potencialmente, pelo menos, perlocucionária também. Note-se o jogo de linguagem de ativação de cenas/enquadres/molduras que se mantêm em latência (à sombra do ponto de vista do desempenho), porém focalizadas/suscitadas do ponto de vista do resgate da memória na dinâmica sociohistórica de semiotização do mundo através da interação verbal. Trata-se da $1^{\text {a }}$ instância por mim

\footnotetext{
${ }^{4}$ Cito aqui este exemplo e o analiso a título de ilustração, por julgá-lo prototipicamente revelador da complexa gama de constructos sociocognitivos dos casos emblemáticos da CM. Entretanto, deixo em suspenso para mais adiante no artigo a análise de um possível subgrupo de contraexemplos ao que ora defendo com minha contribuição a esse periódico.

5 Aos interessados em visualizar a amostra de corpus em banco de dados de mais de 550 instâncias coletadas, favor solicitar cópia a ser enviada por correio eletrônico, mediante o endereço vicentesantosmendes@gmail.com
} 
coletada a partir de rádio e TV que demonstra, fortemente, constituir a CM um padrão individualizado dentre as infinitas variantes construcionais vigentes no PB culto atual que servem para guiar a dinâmica de sinalização do sentido (FAUCONNIER; TURNER, 2002) na constante parceria entre os interlocutores (CLARK, 1996) ao se engajarem numa cena de ação conjunta para darem sentido ao mundo enquanto seres que reconhecem no outro um agente mental e intencional em relações simbólicas rotineiras (TOMASELLO, 1999, 2003).

Bom Dia Brasil 05/01/2006, transcrição a partir de videocópia da matéria requisitada à Rede Globo:

(Chamada): As reformas daquele que já foi o maior do mundo

(Âncora do Bom dia Brasil): Na semana que vem começa a temporada 2006 do futebol brasileiro, com os campeonatos estaduais, as competições de maior rivalidade e tradição. No Rio de Janeiro existe grande expectativa pela reabertura do Maracanã. O estádio ficou fechado no último campeonato brasileiro para uma grande reforma. Vai ser reaberto agora durante o campeonato carioca. Mas isso não significa que ele estará pronto. Longe disso. Vamos ver como anda a mexida no "Maraca".

(VT): O gramado, um tapete: Plantado muda por muda. Novinho em folha para a reabertura do estádio no dia 22. Clássico entre Botafogo e Vasco, pelo campeonato carioca. Mas será um Maracanã pela metade. Houve atraso nas obras e só o anel superior - com arquibancada, cadeiras especiais, tribuna, e cabines de rádio e TV provisórias - estará disponível.

(Responsável pela reforma, ainda no VT): “As novas cabines de... da imprensa, elas serão mais pesadas do que eram... as que tinham (sic) antes. Então ali, teve que ser feito um teste... Então algumas questões de engenharia é que fizeram com que nós atrasássemos a obra".

(De novo o repórter da matéria no vídeo): Durante os campeonatos carioca e brasileiro será assim: funcionamento parcial. Mudanças graduais. Até que o velho "Maraca" ganhe cara nova. A alteração mais significativa em relação ao desenho original do Maracanã só deverá estar concluída no fim de novembro, quase um ano depois do previsto. São as cadeiras que vão se estender até aqui, à beira do gramado. É o traço mais inovador. E também o mais polêmico do projeto. Para que este seja o visual no fim do ano, foi necessário mexer na estrutura do estádio: Rebaixar o campo em $1 \mathrm{~m}$ e $40 \mathrm{~cm}$; elevar os degraus das cadeiras em $60 \mathrm{~cm}$, melhorando a visibilidade para o torcedor. Peso adicional e que será sustentado por novas vigas. Pequenas e grandes obras que vão consumir mais de cem milhões de reais. Mas a modernidade tem um preço que não se calcula em reais. Com o fim da geral, morre um pedaço do folclore do futebol. Acaba, matematicamente, a expressão "maior do mundo" para o estádio e seus 90.000 lugares. Em março de 2007, chegam ao fim as adaptações para receber os jogos pan-americanos. Aos 56 anos, aquele Maracanã do filme preto e branco já não existirá mais. Terá se transformado em um Maracanã colorido, moderno e bem diferente.

(Tadeu Schmidt): Olha, o Maracanã pode até não ser mais o maior do mundo. Mas continua sendo o mais apaixonante, aquele em que os jogadores mais se emocionam, quando jogam pela $1^{a}$ vez. Agora, o sucesso dessas cadeiras aí muito próximas ao campo depende, evidentemente, da educação dos torcedores. É... do pessoal 'num', num fazer confusão ali perto, né, Márcio. Tem que... o pessoal colaborar também para o novo Maracanã ser um sucesso.

(Márcio): Claro, e o novo Maracanã é a melhor, ãhn, prova, de que é possível fazer um estádio moderno sem demolir o Maracanã antigo, como chegaram a propor... Igual fizeram em outros grandes estádios, e tradicionais! estádios mundo afora.

(Maria): E tem que tomar conta desse tempo, que já teve aí milésimo gol de Pelé, despedida do Pelé da seleção brasileira, despedida de Garrincha num amistoso... Mas ninguém precisa lembrar daquela derrota na copa de 50, né, logo depois que abriu, ninguém merece... Tadeu Schmidt!

(T.S.): Exatamente! Agora, de qualquer forma, o Maracanã faz muita falta ao campeonato brasileiro, ao futebol brasileiro. Fez muita falta no último campeonato brasileiro. E pelo que eu vi da grama ali hein, Márcio, você que é um exímio jogador de futebol... (irônico) Deu vontade de jogar ali, hein?!

(Márcio, sorrindo): A grama ali 'tá espetacular. Dá vontade... Até o perna de pau joga bem ali. MUITO bom! Obrigado, Tadeu. 
O que é crucial ressaltar aqui é a pertinência da CM no exato momento de fala em que foi enunciada como deslanchadora simbólica de uma potencialidade rica de significação a fundo enraizada na sociedade, na história e na cultura. Ou seja, através do molde, do padrão 'aquela derrota na copa de 50, logo depois que o Maracanã abriu, ninguém merece!', Maria resgata o incidente da não-conquista do título mundial pela seleção brasileira de futebol. Observe que todo esse conteúdo está destacado pela CM enquanto ativação de Frames. Porém, do ponto de vista da forma, permanece somente tangenciado/pontuado pela expressão linguística que veicula a ocorrência do padrão sintático em uso. O Maracanã é inaugurado para o campeonato mundial em 1950. Na decisão da copa, o Brasil pode até empatar com o Uruguai que a seleção canarinho ainda será a campeã do torneio. Mas depois do gol de Obdúlio Varela, o Uruguai faz 2 a 1 no Brasil, e o país se vê em prantos pelas ruas por ter logrado somente o lugar de vicecampeão na final contra a rival sul-americana, na decisão do mundial em casa no estádio que era - e por tanto tempo continuaria a ser - o maior do mundo! Efetivamente, uma experiência vergonhosa, desagradabilíssima, revoltante para mim, para você e para qualquer outro brasileiro, daí o comentário 'ninguém merece!'. Por ser um fato criticável, do qual devêssemos, caso tal façanha fosse possível, nos redimir, invertendo o resultado e assim, "nos moralizando".

Cabe aqui uma ponderação sobre um possível subgrupo de contraexemplos à CM. Há construções que se inserem no padrão da Construção Moralizante/Moralizadora, porém NÃO constituem instanciações dessa categoria da rede construcional. De fato, elas nem mesmo podem ser classificadas como representativas de uma CTUN. Isso porque:

$\Rightarrow$ O próprio Tópico remete a um referente cuja valoração tende a ser positiva, invertendo, destarte, a natureza da predicação do quantificador universal negativo 'ninguém' ao escopar sobre o verbo do Comentário "merece", "aguenta" etc.

$\Rightarrow$ Por conseguinte, em vez de criticar um estado de coisas, a função comunicativa de tais exemplos é, ao contrário, a de engrandecer sobremaneira o referente do SN/S Tópico em questão.

Demos um exemplo a fim de clarificar a argumentação. "Aquele mulherão da Juliana Paes, ninguém aguenta!" Numa leitura indeterminada, pois não se sabe quem seria o parceiro da beldade, o que se está coconstruindo entre os interactantes a partir dessa expressão linguística é algo do tipo: ela é "areia demais para o caminhão" de qualquer homem. Ou, numa leitura particularizada, "Essa mulher maravilhosa, ninguém aguenta!" (Onde o referencial do SN Tópico seja, de novo, a Juliana Paes). Tal construção será de certo proferida pelo namorado, amante, parceiro, "ficante", "caso" etc. da atriz e indubitavelmente parafraseável como "só eu mesmo, que sou o cara mais sortudo do mundo, tenho a honra de estar sempre com ela, em momentos sociais e em momentos íntimos. Não sei nem como o destino me deu tamanho presente!!!"”.

Um outro exemplo desse tipo, pelo qual também agradeço a um parecerista anônimo, é a construção: "Esse anguzinho, ninguém merece!" A depender do contorno entoacional, do gestual-facial que acompanha o proferimento da construção, enfim, de uma gama de fatores contextuais inerentes a esse uso real da língua que poderíamos chamar de "custo enunciativo", novamente vigora uma predicação inversa ao que seria canônico via CM. Qual seja, pode-se muito bem construir esse enunciado como gatilho de uma carga semântico-pragmática de elogio. Pode sim ser que, dadas as circunstâncias em que se insira esse uso real de língua, o falante/escritor queira dizer, e seja assim interpretado pelo seu ouvinte/leitor algo do tipo: essa delícia de angu é perfeita demais para os padrões dos 
restaurantes atuais, ou para o paladar de seus frequentadores. Ele é como o da cozinheira da minha bisavó, feito na roça, com água de poço, fubá moído em casa de milho orgânico, temperado com manteiga de fabricação própria ou com gordura/banha de porco etc.

Em resumo, parece que podemos aventar a possibilidade, a partir das poucas construções, - autorizadas pela língua e, portanto, dignas de menção e explicação por nossa parte - recolhidas no uso ou oriundas da introspecção dos dois pareceristas anônimos já mencionados, de que exista, mesmo que de ocorrência marcada no PB, um subtipo de construção cuja forma é idêntica ao padrão aqui eleito como objeto de análise mas cuja semântica-pragmática lhe é diametralmente oposta. Vale dizer, em contextos peculiares, em circunstâncias não-canônicas, em situações de custo enunciativo todo próprio, o mesmo formato do padrão instanciador da CM pode traduzir uma Construção de Realce distinta, que poderíamos chamar, por exemplo, de CREAI (Construção de Realce de Excelência Absoluta Incomparável), ou algo que o valha.

\section{Considerações finais}

Creio serem os resultados obtidos pela pesquisa já bastante indicativos de que, sem dúvida, a CM constitui SIM uma construção sintática individualizada dentro da rede de pareamento expressão-modos de significação que materializa no uso a competência comunicativa dos falantes nativos do PB na sua deriva sincrônica atual. Entretanto, a robustez da conclusão aqui apontada poderia, evidentemente, ser corroborada com ainda mais vigor mediante o aporte de recursos peritos da linguística computacional e de corpora, que disponibilizam ferramentas técnicas mais finas no tratamento da informação, tais como Word Smith, Tool Kit, Unitex, Sketch Engine e similares ${ }^{6}$.

A pesquisa aqui abordada insinua com bastante força de indícios que a CM encontra-se entrincheirada e cristalizada como um pareamento forma-sentido discreto recorrente aos falantes nativos do $\mathrm{PB}$ na sua dinâmica incansável de dar sentido ao universo ao seu redor utilizando-se da capacidade semiotizadora que nos singulariza enquanto espécie (LEVINSON; JAISSON: 2006, JABLONKA; LAMB, 2005, inter alia). Mas não a ponto de limitar-se, por exemplo, ao predicador prototípico 'merecer'. A CM ocorre também com outros verbos no Comentário: 'aguentar', 'aturar', 'escolher', 'acreditar'... No fim das contas, que melhor maneira para concisamente erigir um Tópico como foco atencional e predicar dele uma crítica emotivamente forte, situacionalmente ancorada no transcorrer do diálogo até o momento da enunciação e enraizada na sociedade, história e cultura via ativação de frames $^{7}$ que a CM?

Além disso, podem-se citar como ganho teórico adicional os seguintes resultados complementares da investigação da CM aqui discutida:

\footnotetext{
${ }^{6}$ Como, aliás, demonstra com propriedade a investida em Tecnologia da Informação do PPG-Linguística da UFJF ora operante no projeto FrameNet do PB. Esse imbricamento com a informática e os bancos de dados parece ser indispensável na empreitada analítica dos proponentes da agenda de ponta da linguística cognitiva mundial, conforme fazem notar, entre outros, Salomão (1997; 2003); Croft e Cruse (2004); Panther e Thornburg (2007). Mais concretamente, aplicados ao objetivo de esmiuçar ainda mais a CM, pensaria aqui no grau de detalhamento dessas ferramentas peritas que me permitiriam, por exemplo, diferenciar entre 'lemas', 'lexemas' e 'palavras'. Foge-se, dessa maneira, do primitivismo tosco das ferramentas de busca abertas, leigas, que trazem como resultados indistintos todas as ocorrências de um mesmo lexema, independentemente de sua forma na superfície do discurso.

7 O texto chave para compreender esses entrelaçamentos mentais ativados por palavras do discurso, que se mantém atual há mais de 30 anos, é Fillmore (1977).
} 
- A frequência de uso da construção em foco corrobora a classificação do Português do Brasil como língua de proeminência tanto de Tópico quanto de Sujeito (PONTES, 1987; MENDES, 1998; VASCO, 2006; ORSINI, 2006), lado a lado com o japonês, por exemplo, (CHINO, 2001, 2005) só ilustrativamente.

- A análise do banco de dados amostral confirma o papel da organização tópica na constituição da coerência discursiva, validando os processos de elaboração referencial que atuam como mecanismo de articulação tópica (PINHEIRO 2003; 2005; 2006), e sua função na socioconstrução do significado contextualizado em parceria pelos interactantes.

- A abordagem construcional adotada refuta teorias derivacionais de sintaxe, que explicam a linearidade superficial como resultado de movimento de constituintes a partir de uma estrutura profunda subjacente. Reforça, portanto, a visão construcional, segundo a qual as sentenças, tal como ocorrem no uso da língua, instanciam em si um pareamento de forma e sentido, conforme defendem (FILLMORE; KAY; O'CONNOR, 1988; CROFT, 2001; GOLDBERG, 1995; 2005; 2006; JACKENDOFF, 2002; MENDES, 2003 ${ }^{8}$; SALOMÃO, 2005; MARCUSCHI, 2004 e seguidores), deslanchando um rico processo de semiose verbal e ao mesmo tempo salientando a importância da operação de "construal" (perspectivização) nessa dinâmica.

- Investigar interpretativa e empiricamente o que a princípio as pessoas tendem a classificar como "chavão, vício de linguagem, empobrecimento da língua" etc. rebate preconceitos ao revelar configurações mentais e linguísticas intrincadas. E isso contribui para delimitar a competência gramatical e comunicativa dos falantes do PB hoje, na mesma linha que Jesus (2003) apontou para os provérbios e trabalhos recentes de Marcos Bagno, Kanavillil Rajagopalan, Lilian Vieira Ferrari, Dante Luchesi, Magda Soares, Heronides Moura, Helena Martins, Stella Maris Bortoni Ricardo e colegas sustentam.

- A análise alinha a descrição do PB hodierno no arcabouço teórico da Gramática das Construções conforme a concebem Jackendoff (1997), Goldberg (2005; 2006), Goldberg e Jackendoff (2004); vertente desse paradigma distinta, entretanto não ortogonalmente antagônica à ou incompatível com a trilha enveredada pelas demais concepções do antisintactocentrismo que, por exemplo, Fillmore e Kay (1995), Croft (2001), Bergen e Chang (2004) representam.

- Os resultados investigativos obtidos reforçam a tese dos bastidores da cognição humana revelados pela insuficiência do significante, pois abrem para um jogo de linguagem de bússolas verbais fornecedoras de rumos de significação que encampam molduras, cenas, enquadres, inferências, parcerias entre interactantes, arranjos figura e fundo, analogias, metáforas, metonímias, esquemas imagéticos e " $n$ " outras dinâmicas disponíveis aos humanos não só na semiose via língua natural mas na conceptualização do mundo como um todo através de modalidades também não linguísticas de construção de sentido para os fenômenos físicos e socioculturais que constituem nossa história (MENDES 2008; 2005; FAUCONNIER; TURNER 2002; SALOMÃO, 2003; MARCUSCHI, 2004, entre outros).

\footnotetext{
${ }^{8}$ Esse trabalho - sobre o gênero 'Ensinando o caminho' / 'Diretivas de rota' / 'Instruções de percurso' revela-se um dos pioneiros no entendimento da dimensão textual e/ou discursiva de uma Gramática das Construções, quando propõe, precursor, estender esse paradigma ao âmbito da macro-sentença, para além da frase, coadunando-se com análises neste sentido posteriormente abraçadas por Östman (2005), Leino e Östman (2005) e com várias contribuições de Miranda e seus orientandos de mestrado na UFJF.
} 


\section{REFERÊNCIAS}

BARLOW, M.; KEMMER, S. Usage based models of language. Stanford: CSLI, 2000.

BERGEN, B.; CHANG, N. Embodied Construction Grammar in simulation-based language understanding. In: ÖSTMAN, J.-O.; FRIED, M. (eds.) Construction grammars: cognitive grounding and theoretical extensions. Philadelphia/Amsterdam: John Benjamins, 2004. p. 147-190.

BROWN, P.; LEVINSON, S. Politeness: some universals in language usage. In GOODY, E. N. (ed.) Questions and Politeness. Cambridge: Cambridge University Press, 1978. p. 56-289.

BUBLITZ, W. Englische Pragmatik: eine Einführung. Berlin: Ehrig Schmidt Verlag, 2001.

CHINO, N. Joshi de kawaru anata no nihongo [Master the particles and improve your Japanese] Tokyo: Kodansha, 2001.

CHINO, N. Kurabete wakaru nihongo no joshi. [How to tell the difference between Japanese particles] Tokyo: Kodansha, 2005.

CLARK, H. Using language. Cambridge: Cambridge University Press, 1996.

CROFT, W. Radical construction grammar: syntactic theory in typological perspective. Oxford: Oxford University Press, 2001.

CROFT, W.; CRUSE, A. Cognitive linguistics. Cambridge, MA: Cambridge University Press, 2004.

FAUCONNIER, G.; TURNER, M. The way we think: conceptual blending and the mind hidden complexities. New York: Basic Books, 2002.

FILLMORE, C. Scenes-and-frames semantics. In: ZAMPOLLI, A. (ed.) Linguistic structure processing. Amsterdam: North Holland, 1977. p. 55-81.

FILLMORE, C.; KAY, P. Construction grammar. Ms. Distributed by CSLI Publications. Stanford, 1995.

FILLMORE, C.; KAY, P.; O'CONNOR, M. Regularity and idiomaticity in grammatical constructions: the case of 'let alone'. Language, 64, p. 501-538, 1988.

GOLDBERG, A. Constructions at work: the nature of generalization in language. New York: Oxford University Press, 2006.

GOLDBERG, A. Constructions, lexical semantics and the correspondence principle: accounting for generalizations and subregularities in the realization of arguments. In: ERTESCHIK-SHIR, N.; RAPOPORT, T. (eds.) The syntax of aspect. Oxford: Oxford University Press, 2005. p. 215-236.

GOLDBERG, A. Constructions: a construction grammar approach to argument structure. Chicago: University of Chicago Press, 1995.

GOLDBERG, A.; JACKENDOFF, R. The English resultative as a family of constructions. Language 80, 2004, p. 532-568.

JABLONKA, E.; LAMB, M. Evolution in four dimensions: genetic, epigenetic, behavioral, and symbolic variation in the history of life. Cambridge, MA: MIT, 2005. 
JACKENDOFF, R. A user's guide to thought and meaning. New York: Oxford University Press, 2012.

JACKENDOFF, R. Foundations of language: brain, meaning, grammar, evolution. Oxford: Oxford University Press, 2002.

JACKENDOFF, R. Twistin' the night away. Language, 73, p. 534-559, 1997.

JESUS, I. As construções condicionais universais proverbiais: uma abordagem sociocognitiva. Dissertação de Mestrado. Universidade Federal de Juiz de Fora, 2003.

LAMBRECHT, K. Information structure and sentence form. Cambridge: Cambridge University Press, 1994.

LANGACKER R. A usage-based model. In RUDZKA-OSTYN, B. (ed.) Topics in cognitive linguistics. Philadelphia: John Benjamins, 1988. p. 49-90.

LEINO, J.; ÖSTMAN, J.-O. Constructions and variability. In: FRIED, M.; BOAS, H.C. (eds.) Grammatical constructions: back to the roots. Amsterdam/Philadelphia: John Benjamins, 2005. p. 191-214.

LEVINSON, S.; JAISSON, P. (eds.) Evolution and culture: a Fyssen foundation symposium. Cambridge, MA: MIT, 2006.

LEVINSON, S. Pragmatics. Cambridge, MA: Cambridge University Press, 1983.

MARCUSCHI, L. A. Atividades de referenciação, inferenciação e categorização na produção de sentido. In: MARCUSCHI, L. Cognição, linguagem e práticas interacionais. Rio de Janeiro: Lucerna, 2007. p. 82-103.

MARCUSCHI, L. O léxico: lista, rede, ou cognição social? In: NEGRI, L; FOLTRAN, M. J.; OLIVEIRA, R.P. (orgs.) Sentido e significação. Em torno da obra de Rodolfo Ilari. São Paulo: Contexto, 2004. p. 263-284.

MATHEWS, P. H. Oxford Concise Dictionary of Linguistics. Oxford: Oxford University Press, 1997. p. 125. ['face' entry]

MENDES, V. Certain topic constructions in Japanese and Brazilian Portuguese: a contrastive study. Sophia University Master's Thesis. Tokyo. Series reference 96-0338, 1998.

MENDES, V. I'll teach you how to get there: breaking down a text genre. (Submetido como capítulo potencial a EVANS, V.; CHILTON, P. (eds.) Language, cognition and space: the state of the art and new directions. London: Equinox, 2010). (inédito)

MENDES, V. Route directions conceptualization: a counterargument for the autonomy of syntax. Paper given at the $8^{\text {th }}$ International Cognitive Linguistics Conference. General Session. Logroño, Spain. Universidad de la Rioja. July, 23, 2003.

MENDES, V. Spatial "metametaphors" concerning life: a cognitive holistic approach. Veredas, v. 2, p. 1-11, 2011.

MENDES, V. The semantics-pragmatics of route directions: Unveiling the complexity inherent to a subfield of German language-and-thought backstage spatial cognition. Saarbrücken: Verlag Doktor Müller, 2008. [Versão impressa em forma de livro da contraparte publicada em meio digital quando da obtenção do doutorado The semanticspragmatics of route directions. Hamburg University Ph.D. dissertation. Published online: http://www.sub.uni-hamburg.de/opus/volltexte/2005/2410 2005]. 
ORSINI, M. As construções de tópico no Português do Brasil. Linguagem em (Re)vista, 3 e 4. p. 15-25, 2006.

ÖSTMAN, J.-O. Construction discourse: A prolegomenon. In: ÖSTMAN, J.-O.; FRIED, M. (eds.) Construction grammars: cognitive grounding and theoretical extensions. Amsterdam: John Benjamins, 2005. p. 121-44.

PANTHER, K.-U.; THORNBURG, L. Metonymy. In: CUYCKENS, H.; GEERAERTS, D. (eds.) The Oxford handbook of cognitive linguistics. Oxford: Oxford University Press, 2007. p. 236-263.

PERINI, M. Princípios de lingüística descritiva: introdução ao pensamento gramatical. São Paulo: Parábola, 2006.

PINHEIRO, C. Estratégias textuais-interativas: a articulação tópica. Maceió: EDUFAL, 2005.

PINHEIRO, C. Interação de fatos formulativos e interacionais na construção do texto: um estudo sobre o uso de formas referenciais na organização tópica. Linguagem em (Dis)Curso 4(1), p. 37-64, 2003.

PINHEIRO, C. O tópico discursivo como categoria analítica textual-interativa. Cadernos de Estudos Lingüísticos 48(1), p. 43-51, 2006.

PONTES, E. O tópico no português do Brasil. São Paulo: Ática, 1987.

SALOMÃO, M. Gramática e interação: o enquadre programático da hipótese sóciocognitiva sobre a linguagem. Veredas, 1(1), p. 23-39, 1997.

SALOMÃO, M. O problema da especificação da estrutura argumental: Voltas sobre o tema 'léxico ou sintaxe'. In: MIRANDA, N.; NAME, C. (orgs.) Lingüística e cognição. Juiz de Fora: Ed. da UFJF, 2005. p. 121-140.

SALOMÃO, M. Razão, realismo e verdade: o que nos ensina o estudo sociocognitivo da referência. Cadernos de Estudos Lingüísticos, 44, p. 71-84, 2003.

SALOMÃO, M. Teorias da linguagem: a perspectiva sociocognitiva. In: MIRANDA, N. S; SALOMÃO, M. M. M. Construções do português do Brasil. Da gramática ao discurso. Belo Horizonte: Editora UFMG, 2009. p. 20-32.

SALOMÃO, M.; MARCUSCHI, L.-A. Introdução. In: MUSSALIM , F.; BENTES, A.C. (orgs.) Introdução à lingüística. Vol. 3. Fundamentos epistemológicos. São Paulo: Cortez, 2004. p.13-26.

SARDINHA, T. B. Lingüística de corpus. São Paulo: Manole, 2004.

TOMASELLO, M. Constructing a language: a usage-based theory of language acquisition. Cambridge, MA: Harvard University Press, 2003.

TOMASELLO, M. The cultural origins of human cognition. Cambridge, MA: Harvard University Press, 1999.

VASCO, S. Construções de tópico na fala popular. Tese de doutorado. UFRJ, 2006.

Recebido em setembro de 2011.

Aprovado em outubro de 2012. 